\title{
Long-term effects of early antibiotic intervention on blood parameters, apparent nutrient digestibility, and fecal microbial fermentation profile in pigs with different dietary protein levels
}

\author{
Miao Yu, Chuanjian Zhang, Yuxiang Yang, Chunlong Mu, Yong Su, Kaifan Yu and Weiyun Zhu*
}

\begin{abstract}
Backgroud: This study aimed to determine the effects of early antibiotic intervention (EAl) on subsequent blood parameters, apparent nutrient digestibility, and fecal fermentation profile in pigs with different dietary crude protein (CP) levels. Eighteen litters of piglets (total 212) were randomly allocated to 2 groups and were fed a creep feed diet with or without in-feed antibiotics (olaquindox, oxytetracycline calcium and kitasamycin) from postnatal $\mathrm{d} 7$ to $d 42$. On $d 42$, the piglets within the control or antibiotic group were mixed, respectively, and then further randomly assigned to a normal- (20\%, 18\%, and 14\% CP from d 42 to $d 77, d 77$ to d 120, and d 120 to $d$ 185, respectively) or a low-CP diet (16\%, 14\%, and 10\% CP from d 42 to d 77, d 77 to d 120, and d 120 to d 185, respectively), generating 4 groups. On d 77 (short-term) and d 185 (long-term), serum and fecal samples were obtained for blood parameters, microbial composition and microbial metabolism analysis.

Results: EAl increased $(P<0.05)$ albumin and glucose concentrations in low-CP diet on $\mathrm{d} 77$, and increased $(P<0.05)$ urea concentration in normal-CP diet. On d 185, EAl increased $(P<0.05)$ globulin concentration in normal-CP diets, but decreased glucose concentration. For nutrient digestibility, EAl increased $(P<0.05)$ digestibility of CP on d 77. For fecal microbiota, the EAl as well as low-CP diet decreased $(P<0.05)$ E. coli count on $d$ 77. For fecal metabolites, on $d 77$, EAl decreased $(P<0.05)$ total amines concentration but increased skatole concentration in low-CP diet. On d 185, the EAl increased $(P<0.05)$ putrescine and total amines concentrations in low-CP diets but reduced $(P<0.05)$ in the normal-CP diets. The low-CP diet decreased the concentrations of these compounds.
\end{abstract}

Conclusions: Collectively, these results indicate that EAI has short-term effects on the blood parameters and fecal microbial fermentation profile. The effects of EAI varied between CP levels, which was characterized by the significant alteration of glucose and putrescine concentration.

Keywords: Antibiotics long term effect, Antimicrobial, Blood parameters, Low protein diet, Metabolites, Microbiota

\footnotetext{
* Correspondence: zhuweiyun@njau.edu.cn

Jiangsu Key Laboratory of Gastrointestinal Nutrition and Animal Health,

Laboratory of Gastrointestinal Microbiology, College of Animal Science and

Technology, Nanjing Agricultural University, Nanjing, Jiangsu 210095, China
} 


\section{Background}

In intensive swine husbandry systems, piglets commonly receive in-feed antibiotics during early life stage, mainly aiming to prevent outbreaks of respiratory and gastrointestinal tract (GIT) infections, and promote growth [1]. However, their enormous and uncontrolled use has led to many resistant bacterial strains, causing detrimental effects in both humans and animals. In China, although the use of antibiotics in feed during weaning period of the pig is still a common practice, it has increasingly received safety concerns from consumers and thus the use of antibiotics in feed will be banned in the future. Thus, to better design alternatives to antibiotics for pigs, it is important to understand the post-term effect and the possible mode of action of the antibiotics. The immediate effects of antibiotic intervention on blood parameters [2], apparent nutrient digestibility [3], gut bacterial composition $[4,5]$ and microbial metabolism $[6,7]$ have been described, especially in newly weaned pigs. However, much less attention has been paid to antibiotics intervention in suckling and nursing stage and long-term (carry-over) effects on host metabolism and GIT microbiota after withdrawal of antibiotics. In pigs, early life antibiotic exposure affected pancreatic development and glucose metabolism 5 wk after antibiotic withdrawal [8]. A recent study found piglets that received an subcutaneous injection with $0.1 \mathrm{~mL}$ tulathromycin (dosage $2.5 \mathrm{mg} / \mathrm{kg}$ body weight) on $\mathrm{d} 4$ after birth showed decreased microbial diversity and an altered microbial composition in jejunal digesta on d 176, but had limited effect on d 56 [9]. Using mice models, previous studies also have indicated that low-dose antibiotic exposure in early life had a longterm effect on host metabolism and adiposity $[10,11]$. These results suggest that alteration of gut microbes at early life may have long-lasting effect on subsequent host metabolism and gut microbiota. However, it is still unclear whether the early use of antibiotics in suckling and nursing stage have long-term impact on subsequent metabolism and gut microbes in pigs.

In addition to the early use of antibiotics, dietary protein level could also affect the gut health of the animal [12]. In practice, low-protein amino acid-supplementation diets are used to decrease nitrogen excretion and feed costs. Our previous study found that low crude protein (low-CP) diet increased the counts of Bacteroidetes, Clostridium cluster IV and Clostridium cluster XIVa, decreased Escherichia coli counts, and decreased cadaverine, phenol and indole compounds concentrations [13, 14], suggesting a beneficial effect of low-CP diet. Antibiotics could decrease the nutrient utilization by gut microbiota and increase those available for body metabolism [15]. However, when fed low-CP diet, whether early antibiotic intervention affect body metabolism and fecal microbial fermentation profile in pigs remains unclear.
To test the hypothesis that early antibiotic intervention (EAI) (from d 7 to d 42) may have long-lasting effects on subsequent host metabolism and GIT microbes and microbial fermentation in pigs, the present study examined the blood parameters, apparent nutrient digestibility, and major bacterial taxonomic groups and microbial metabolism in feces on d 77 (short-term) and d 185 (long-term) in relation to different CP diets.

\section{Methods}

\section{Animals and experimental design}

A total of 18 litters crossbred (Duroc $\times$ Landrace $\times$ Large White) newborn piglets (212 piglets in total) were used in this study. The piglets on $\mathrm{d} 7$ while with the sow were randomly allotted to two groups $(n=9$ litters $)$ and offered creep feed (Additional file 1: Table S1) either without (control) or with a mixture of antibiotics $(50 \mathrm{mg} / \mathrm{kg}$ oxytetracycline calcium, $50 \mathrm{mg} / \mathrm{kg}$ kitasamycin, and $50 \mathrm{mg} / \mathrm{kg}$ olaquindox) (antibiotic). This mixture of antibiotics is commonly used as a growth promoter for piglets in commercial farms in China in order to ensure healthy transition around weaning. Oxytetracycline calcium is a broad spectrum antibiotic with antibacterial activity against gram-negative and gram-positive bacteria, and kitasamycin exhibits activity mainly against grampositive bacteria, whereas olaquindox exhibits antibacterial activity both gram-negative and gram-positive bacteria. The dosages for the antibiotics used were according to the dose limitation in Regulations of Feeding Drug Additives (announcement No. 168) approved by Ministry of Agriculture, China. On d 23, the sows were removed from the piglets, while the piglets remained in the environmentalcontrolled nursery with $1.8 \times 2.5 \mathrm{~m}$ pens fitted with a hard plastic fully slotted floor, and fed the same creep feed until $\mathrm{d} 42$, which is a typical feeding program in a commercial farms in China. On d 42, the piglets within the control or antibiotic group were mixed, respectively, and then randomly allotted to 1 of 2 dietary treatments (Low-crude protein, Low-CP; Normal-crude protein, Normal-CP, respectively) according to their equal average body weight (BW) and gender, respectively, which generated 4 groups (Control-Low CP, Con-LP; Control-normal CP, Con-NP; Antibiotic-Low CP, Ant-LP; AntibioticNormal CP, Ant-NP, respectively). There were 5 pens replicates per treatment group and 9 pigs per pen. The numbers of barrows and gilts were not equal on $d 42$, but spilt as evenly as possible across treatments (23 gilts and 22 barrows, 22 gilts and 23 barrows, 24 gilts and 21 barrows, and 23 gilts and 22 barrows for treatments Con-LP, Con-NP, Ant- LP, and Ant- NP, respectively).

The diets comprised a normal-CP diet $(20 \%, 18 \%$, and $14 \% \mathrm{CP}$ during d 42 to $\mathrm{d} 77, \mathrm{~d} 77$ to $\mathrm{d} 120$, and $\mathrm{d} 120$ to $\mathrm{d}$ 185 , respectively, supplemented with lysine, methionine, threonine, and tyrptophan) and a low-CP $\operatorname{diet}(16 \%, 14 \%$, 
and $10 \% \mathrm{CP}$ during $\mathrm{d} 42$ to $\mathrm{d} 77, \mathrm{~d} 77$ to $\mathrm{d} 120$, and $\mathrm{d} 120$ to $\mathrm{d} 185$, respectively, supplemented with four limiting AA mentioned above) (Table 1). The 2 diets were formulated to meet or exceed NRC [16] nutrient recommendations. Creep feed diets were fed as crumble, whereas normal- or low-CP diets were in a pelleted form. After d 42 , the pigs were moved to a total confinement house with $2.5 \times 3.0 \mathrm{~m}$ pens that had partial concrete slatted floors. During the experimental period, the pigs consumed feed ad libitum and feed residues were recorded daily. All pigs had free access to water via a low-pressure nipple drinker. The body weight (BW) of pigs was recorded at the beginning of the experiment and at the end of each period to determine average daily gain (ADG), average daily feed intake (ADFI), and the ratio of gain to feed (G:F).

\section{Sample collection and preparation}

The fecal samples were collected for 3 consecutive days, from d 75 to 77 and 183 to 185 of age, respectively, during the feeding period in the morning by rectal stimulation. Feces from each day were collected at least 3 pigs from each of the pen replicates and were pooled for each replicate to create composite samples. The feces were then frozen at $-20{ }^{\circ} \mathrm{C}$ until the analysis of microbial metabolites and dominant bacterial community, which was completed within 2 weeks after sample collection.

On d $77(28.4 \pm 0.6 \mathrm{~kg})$ and d $185(102.0 \pm 0.6 \mathrm{~kg})$, when the experimental pigs were fasted for approximately $12 \mathrm{~h}$, one median BW barrow from each pen was selected for blood sampling $(n=5)$. Blood samples $(10 \mathrm{~mL})$ were collected from the jugular vein and serum

Table 1 Ingredient and nutrient composition of experimental diets (\%, as-fed basis) ${ }^{a}$

\begin{tabular}{|c|c|c|c|c|c|c|}
\hline \multirow{2}{*}{$\begin{array}{l}\text { Age range, d: } \\
\text { Ingredient, \% }\end{array}$} & \multicolumn{2}{|l|}{42 to 77} & \multicolumn{2}{|c|}{77 to 120} & \multicolumn{2}{|c|}{120 to 185} \\
\hline & LP-16\% & NP-20\% & LP-14\% & NP-18\% & LP-10\% & NP-14\% \\
\hline Corn & 68.00 & 63.70 & 68.90 & 58.00 & 82.40 & 71.10 \\
\hline Soybean meal & 18.00 & 21.00 & 18.80 & 29.38 & 8.71 & 19.13 \\
\hline Wheat bran & - & - & 6.00 & 8.00 & 2.00 & 4.00 \\
\hline Whey power & 4.30 & 4.30 & - & - & - & - \\
\hline Fishmeal & 3.20 & 8.00 & - & - & - & - \\
\hline Soybean oil & 2.70 & 0.70 & 2.56 & 1.60 & 2.50 & 2.00 \\
\hline Dicalcium phosphate & 0.85 & 0.10 & 0.78 & 0.65 & 0.90 & 0.80 \\
\hline Calcium carbonate & 0.50 & 0.36 & 0.89 & 0.89 & 0.82 & 0.90 \\
\hline Sodium chloride & 0.30 & 0.30 & 0.30 & 0.30 & 0.30 & 0.30 \\
\hline Vitamin mixture $^{b}$ & 0.20 & 0.20 & 0.20 & 0.20 & 0.20 & 0.20 \\
\hline Mineral mixture ${ }^{b}$ & 0.80 & 0.80 & 0.80 & 0.80 & 0.80 & 0.80 \\
\hline L-Lysine & 0.65 & 0.33 & 0.49 & 0.17 & 0.78 & 0.48 \\
\hline DL-Methionine & 0.20 & 0.09 & 0.10 & - & 0.20 & 0.11 \\
\hline L-Threonine & 0.24 & 0.10 & 0.15 & 0.01 & 0.30 & 0.15 \\
\hline L-Tryptophane & 0.06 & 0.02 & 0.03 & - & 0.09 & 0.03 \\
\hline \multicolumn{7}{|l|}{ Calculated content ${ }^{c}, \%$} \\
\hline$M E^{d}, M J / k g$ & 14.02 & 14.02 & 13.82 & 13.80 & 13.81 & 13.82 \\
\hline \multicolumn{7}{|l|}{ SID AA ${ }^{e}, \%$} \\
\hline Lysine & 1.23 & 1.23 & 0.99 & 0.98 & 0.98 & 0.99 \\
\hline Methionine + Cysteine & 0.68 & 0.68 & 0.56 & 0.56 & 0.60 & 0.56 \\
\hline Threonine & 0.73 & 0.73 & 0.59 & 0.60 & 0.61 & 0.60 \\
\hline Trptophane & 0.20 & 0.20 & 0.17 & 0.20 & 0.18 & 0.17 \\
\hline \multicolumn{7}{|c|}{ Analyzed nutrient composition ${ }^{f}, \%$} \\
\hline Crude protein & 16.63 & 20.11 & 14.03 & 18.02 & 10.18 & 14.06 \\
\hline
\end{tabular}

${ }^{a}$ The pigs of control and antibiotic groups were divided to 1 of 2 treatment groups (normal vs. low CP diet) after $\mathrm{d} 42$. LP low protein diet, NP normal protein diet bProvided per kilogram of diet: vitamin $A, 2.85$ million IU; vitamin $D_{3}, 0.6$ million IU; vitamin $E, 67.50$ IU; vitamin $K_{3}$, 750 mg; vitamin $B_{1}, 750$ mg; vitamin $B_{2}$, 1500 mg; vitamin $B_{6}, 900$ mg; vitamin $B_{12}, 7.5$ mg; nicotinic acid, 7500 mg; folic acid, 300 mg; calcium pantothenate, 3750 mg; biotin, 37.5 mg; vitamin $B_{4}$,

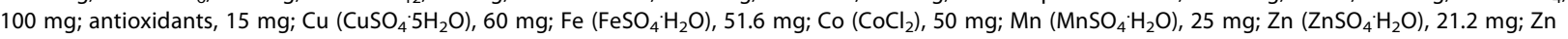
$(\mathrm{ZnO}), 6 \mathrm{mg}$; I (KI), 3.9 mg; $\mathrm{Se}\left(\mathrm{Na}_{2} \mathrm{SeO}_{3}\right), 3.0 \mathrm{mg}$; Carrier (Sepiolite) $604.3 \mathrm{mg}$

${ }^{\mathrm{C}}$ Calculate values according to NRC [16]

${ }^{\mathrm{d}} \mathrm{ME}=$ metabolizable energy

eSID AA = standardized ileal digestible $A A$

${ }^{f}$ Analytical results obtained according to AOAC [17] 
was obtained by centrifuging at $3000 \times g$ for $10 \mathrm{~min}$ at $4{ }^{\circ} \mathrm{C}$. Thereafter, samples were stored at $-20{ }^{\circ} \mathrm{C}$ until chemical analysis.

\section{Nutrient composition and apparent digestibility analysis} The dry matter (DM; procedure 930. 15; AOAC, 2007), crude protein $(\mathrm{CP} ; \mathrm{N} \times 6.25$; procedure 990.03; AOAC, 2007), crude fat (procedure 2003. 06; AOAC, 2007), ash (procedure 942.05; AOAC, 2007), contents of experimental diets and freeze-dried feces were analyzed according to the procedure of the Association of Official Analytical Chemists (AOAC) [17]. The acid insoluble ash (AIA) concentrations were analyzed by the method of ISO (method no.5985; ISO, 2003) [18]. Total tract apparent digestibility of nutrients was calculated based on the content of AIA as a marker in feed and feces, as previously described [19].

\section{Serum biochemical parameters}

Serum total protein, albumin, glucose, urea, cholesterol, triglyceride, high density lipoprotein-cholesterol (HDLC), and low density lipoprotein-cholesterol (LDLC) were measured by the enzymatic colorimetric method using an AU2700 autoanalyzer (Olympus, Tokyo, Japan). Globulin concentration of individual serum samples was calculated by subtracting the amount of albumin from the total protein concentration.

\section{DNA extraction and quantitative real-time PCR}

The total bacterial DNA was extracted from fecal samples $(0.3 \mathrm{~g})$ using the bead-beating and phenol-chloroform extraction methods [20]. The qPCR assay was performed on StepOnePlus ${ }^{\mathrm{Tu}}$ Real-Time PCR System (Life Technologies, Califormia, USA) with SYBR Premix Ex Taq dye (Takala, Bio, Ostu, Japan). The sequences of the selected targets and primers are listed in Table 2 . The reaction mixture

Table 2 Primers used for quantification in this study

\begin{tabular}{lll}
\hline Target & Primer sequence ${\text { 5' } \rightarrow 3^{\prime}}^{\prime}$ & Reference \\
\hline Total bacteria & Forward: CGGTGAATACGTTCYCGG & {$[38]$} \\
& Reverse: GGWTACCTTGTACGACTT & \\
Firmicutes & Forward: GGAGYATGTGGTTAATTCGAAGCA & {$[39]$} \\
& Reverse: AGCTGACGACAACCATGCAC & \\
Bacteroidetes & Forward: GGARCATGTGGTTAATTCGATGAT & {$[39]$} \\
& Reverse: AGCTGACGACAACCATGCAG & \\
Clostridium IV & Forward: GCACAAGCAGTGGAGT & {$[40]$} \\
& Reverse: CTTCCTCCGTTTGTCAA & \\
Clostridium & Forward: CGGTACCTGACTAAGAAGC & {$[41]$} \\
XIVa & Reverse: AGTTTATTCTTGCGAACG & \\
E.coli & Forward: CATGCCGCGTGTATGAAGAA & {$[42]$} \\
& Reverse: CGGGTAACGTCAATGAGCAAA & \\
Lactobacillus & Forward: AGCAGTAGGGATCTTCCA & {$[43]$} \\
& Reverse: ATTCCACCGCTACACATG & \\
\hline
\end{tabular}

$(20 \mu \mathrm{L})$ consist of $10.0 \mu \mathrm{L}$ SYBR Green Supermix (BioRad), $0.4 \mu \mathrm{L}$ ROX Reference Dye, $2.0 \mu \mathrm{L}$ of template DNA, $6.8 \mu \mathrm{L}$ of double distilled water, and $0.4 \mu \mathrm{L}$ of each primer set. The standard curves of each bacterial group were generated with 10 -fold serial dilutions of the $16 \mathrm{~S}$ rRNA genes amplified from the respective target strains. Quantitative real-time PCR amplification was performed using the following conditions: initial denaturation program $\left(95^{\circ} \mathrm{C}\right.$ for $\left.30 \mathrm{~s}\right)$, denaturation program repeated for 40 cycles $\left(95{ }^{\circ} \mathrm{C}\right.$ for $5 \mathrm{~s}, 60{ }^{\circ} \mathrm{C}$ for $30 \mathrm{~s}$ ), followed by the melting curve program $\left(60-95{ }^{\circ} \mathrm{C}\right.$ with a heating rate of $0.1{ }^{\circ} \mathrm{C} / \mathrm{s}$ ). The melting curves were checked after amplification to ensure single product amplification of consistent melting temperature. Quantification was performed in triplicate, and the mean $\mathrm{Ct}$ value was calculated. The results were expressed as $\log _{10} 16 \mathrm{~S}$ ribosomal DNA gene copies/g feces.

\section{Measurement of fecal microbial metabolites}

The short-chain fatty acid (SCFA), amines, ammonia, and phenolic and indolic compounds were selected as markers of GIT microbiota metabolism. The concentrations of SCFA were analyzed by gas chromatography as described previously [21], with slight modifications. Briefly, approximately $0.4 \mathrm{~g}$ of fecal samples were weighed into a $2-\mathrm{mL}$ centrifuge tube, $1.6 \mathrm{~mL}$ of double distilled water was added. The mixture was vortexed for 10 min until the material was homogenized and then centrifuged at $13,000 \times g$ for $10 \mathrm{~min}$ at $4{ }^{\circ} \mathrm{C}$. A portion of $1 \mathrm{~mL}$ of the clear supernatant was transferred into a new tube, and then added $0.2 \mathrm{~mL} \mathrm{25 \%}(w / v)$ metaphosphoric acid. After homogenization, the mixture was frozen at $-20{ }^{\circ} \mathrm{C}$ and kept overnight to precipitate the proteins. After thawing, a portion of $100 \mu \mathrm{L}$ internal standard $(0.64 \%(w / v)$ crotonic acid solution) was added. The tubes were vortexed for $1 \mathrm{~min}$ and then centrifuged at $13,000 \times g$ for $10 \mathrm{~min}$ at $4{ }^{\circ} \mathrm{C}$. The supernatant was filtered through a $0.22-\mu \mathrm{m}$ syringe filter and then analyzed on an Aglient $7890 \mathrm{~B}$ system with a flame ionization detector (Agilent Technologies Inc.). The following column conditions were used: nitrogen was used as the carrier gas with a flow rate of $(17.68 \mathrm{~mL} / \mathrm{min})$; the oven, detector and injector port temperature were $130{ }^{\circ} \mathrm{C}$, $250{ }^{\circ} \mathrm{C}, 220{ }^{\circ} \mathrm{C}$, respectively. These acids were identified by their specific retention times and the concentrations determined and expressed as umol/g.

Amine concentrations in feces were determined by high-performance liquid chromatography (HPLC) with a method according to Yang et al. [22]. Briefly, $1.5 \mathrm{~g}$ of feces were treated with $3 \mathrm{~mL}$ of $5 \%$ trichloroacetic acid, homogenized for $10 \mathrm{~min}$ and then centrifuged at $3600 \times g$ for $10 \mathrm{~min}$ at $4{ }^{\circ} \mathrm{C}$. The supernatant was mixed with an equal volume of $\mathrm{n}$-hexane and vortexed for $5 \mathrm{~min}$, the water phase $(0.5 \mathrm{~mL})$ was transferred into a new tube, 
and then added with $1.5 \mathrm{~mL}$ saturated $\mathrm{Na}_{2} \mathrm{CO}_{3}, 1 \mathrm{~mL}$ dansyl chloride, and $1 \mathrm{~mL} \mathrm{NaOH}(2 \mathrm{~mol} / \mathrm{L})$. The mixed solution was heated at $60{ }^{\circ} \mathrm{C}$ for $45 \mathrm{~min}$, and then added with $100 \mu \mathrm{L}$ ammonia (2.8\%) to stop the reaction. The mixture was kept in the water bath until the acetone was vaporized under nitrogen at $40{ }^{\circ} \mathrm{C}$. Finally, the sample was extracted with $3 \mathrm{~mL}$ diethyl ether. The extracts were dried under nitrogen and then re-dissolved in acetonitrile. The mixture filtered through $0.22-\mu \mathrm{m}$ syringe filter and then analyzed on an Aglient 1220 Infinity LC system with an UV detector (Agilent Technologies Inc.).

The ammonia concentration in feces was analyzed using UV spectrophotometer according to Chaney and Marbach [23]. Phenolic and indolic compounds concentration was determined by HPLC as previously described [24]. Briefly, $0.1 \mathrm{~g}$ of fecal sample was treated with $1 \mathrm{~mL}$ acetonitrile, homogenized for $10 \mathrm{~min}$ and then frozen at $-20{ }^{\circ} \mathrm{C}$ for $20 \mathrm{~min}$. Finally, the mixture was centrifuged at $3000 \times g$ for $10 \mathrm{~min}$ at $4{ }^{\circ} \mathrm{C}$. The supernatant was filtered through a $0.22-\mu \mathrm{m}$ syringe filter and analyzed for phenolic and indolic compounds (i.e., $p$ cresol, skatole, indole, and phenol) using HPLC with an UV detector (Agilent Technologies Inc.).

\section{Statistical analysis}

All data were analyzed using $2 \times 2$ factorial MIXED procedure of SAS for a randomized complete block design (SAS 9.2 Institute, Cary, NC, USA). The model included the fixed effect of antibiotic, protein level, associated twointeractions and the random errors of a pen or an individual pig. The ADG, ADFI, G:F, digestibility of nutrients, and fecal fermentation profile were evaluated using the pen as the experimental unit. Blood parameters were assessed using the individual pig as the experimental unit. Differences were considered significant at $P \leq 0.05$, and tendency was declared with $0.05<P<0.10$. When a significant interaction among antibiotic and $\mathrm{CP}$ was observed, data were further analyzed by using a one-way ANOVA with Duncan's multiple range tests. Differences at $P<0.05$ were identified significant.

\section{Results}

\section{Growth performance and apparent nutrient digestibility}

Growth performance of the pigs was shown in Table 3. For ADG, there was an interaction $(P<0.05)$ between EAI and dietary CP treatment from d 77 to $\mathrm{d} 185$ and $\mathrm{d}$ 42 to $\mathrm{d} 185$. The EAI increased ADG $(P<0.05)$ from $\mathrm{d}$ 42 to $\mathrm{d} 185$ in the low-CP diets but not in the normal$\mathrm{CP}$ diets. Meanwhile, low-CP diet tended to reduce the ADFI $(P=0.08)$ from $\mathrm{d} 42$ to $\mathrm{d} 185$, but G:F at each feeding period did not differ among treatments.

For apparent nutrient digestibility, no interactions between EAI and dietary CP treatment were observed (Table 4). On d 77, there was no difference of OM digestibility among treatments. The EAI significantly increased CP digestibility $(P<0.05)$ and tended to increase $(P=0.06)$ DM digestibility. The low-CP diet reduced $\mathrm{CP}$ and crude fat digestibility $(P<0.05)$. On d 185, digestibility of crude fat was decreased $(P<0.001)$ when pigs fed the low-CP diet, but DM, CP, and OM digestibility were not affected by treatment. Overall, these results indicated that EAI had short-term effect on nutrient digestibility.

Table 3 Effects of early antibiotic intervention on growth performance of pigs with different protein level diets ${ }^{1}$

\begin{tabular}{|c|c|c|c|c|c|c|c|c|}
\hline \multirow[t]{2}{*}{ Item } & \multicolumn{2}{|c|}{ LoW-CP } & \multicolumn{2}{|c|}{ Normal- CP } & \multirow[t]{2}{*}{ SEM } & \multicolumn{3}{|c|}{$P$-value ${ }^{2}$} \\
\hline & $\overline{C o n}$ & Ant & $\overline{C o n}$ & Ant & & $\overline{\text { Ant }}$ & $C P$ & Ant $\times C P$ \\
\hline $42 \mathrm{~d}$ BW, kg & 12.23 & 12.20 & 12.28 & 12.25 & 0.07 & 0.851 & 0.743 & 0.981 \\
\hline \multicolumn{9}{|l|}{$\mathrm{ADG}, \mathrm{kg} / \mathrm{d}$} \\
\hline d 42 to 77 & 0.50 & 0.52 & 0.51 & 0.51 & 0.02 & 0.686 & 0.972 & 0.786 \\
\hline d 77 to 185 & $0.78^{b}$ & $0.81^{\mathrm{ab}}$ & $0.84^{\mathrm{a}}$ & $0.83^{\mathrm{a}}$ & 0.01 & 0.361 & 0.002 & 0.048 \\
\hline d 42 to 185 & $0.71^{b}$ & $0.74^{\mathrm{a}}$ & $0.76^{\mathrm{a}}$ & $0.75^{\mathrm{a}}$ & 0.01 & 0.180 & 0.001 & 0.019 \\
\hline \multicolumn{9}{|l|}{$\mathrm{ADFl}, \mathrm{kg} / \mathrm{d}$} \\
\hline d 42 to 77 & 0.72 & 0.72 & 0.78 & 0.78 & 0.02 & 0.945 & 0.140 & 0.993 \\
\hline d 77 to 185 & 2.24 & 2.36 & 2.44 & 2.54 & 0.06 & 0.349 & 0.119 & 0.891 \\
\hline d 42 to 185 & 1.85 & 1.94 & 2.02 & 2.09 & 0.05 & 0.368 & 0.089 & 0.895 \\
\hline \multicolumn{9}{|l|}{ G:F } \\
\hline d 42 to 77 & 0.70 & 0.73 & 0.67 & 0.66 & 0.02 & 0.880 & 0.227 & 0.675 \\
\hline d 77 to 185 & 0.36 & 0.35 & 0.36 & 0.33 & 0.01 & 0.323 & 0.787 & 0.655 \\
\hline d 42 to 185 & 0.44 & 0.44 & 0.44 & 0.42 & 0.01 & 0.555 & 0.414 & 0.605 \\
\hline
\end{tabular}

\footnotetext{
${ }_{\mathrm{a}, \mathrm{b}}^{\mathrm{b}}$ Means in the same row with different superscripts differ $(P<0.05)$
}

${ }^{1}$ The commercial creep feed with or without in-feed antibiotics $(50 \mathrm{mg} / \mathrm{kg}$ olaquindox, $50 \mathrm{mg} / \mathrm{kg}$ oxytetracycline calcium, and $50 \mathrm{mg} / \mathrm{kg}$ kitasamycin) was fed to pig from $d 7$ to $d 42$. Thereafter, the Con and Ant group were further randomly assigned to provide a normal $(20 \%, 18 \%, 14 \%$ CP from $d 42$ to $d 77, d 77$ to $d$ 120 , d 120 to d 185, respectively) or low CP diet (16\%, 14\%, 10\% CP from d 42 to $d 77$, d 77 to d 120, d 120 to d 185, respectively), respectively

${ }^{2}$ The $P$ values indicate main effects for antibiotic (Ant), protein level (CP) and their interaction (Ant $x(\mathrm{CP})$, respectively 
Table 4 Effects of early antibiotic intervention on total tract apparent digestibility of pigs with different protein level diets ${ }^{a}$

\begin{tabular}{|c|c|c|c|c|c|c|c|c|}
\hline \multirow[t]{2}{*}{ Item, \% } & \multicolumn{2}{|c|}{ Low-CP } & \multicolumn{2}{|c|}{ Normal-CP } & \multirow[t]{2}{*}{ SEM } & \multicolumn{3}{|c|}{$P$-value ${ }^{2}$} \\
\hline & Con & Ant & Con & Ant & & Ant & $C P$ & Ant $\times \mathrm{CP}$ \\
\hline \multicolumn{9}{|l|}{ d 77} \\
\hline $\mathrm{DM}$ & 75.24 & 76.73 & 74.81 & 80.52 & 0.98 & 0.065 & 0.368 & 0.263 \\
\hline $\mathrm{CP}$ & 60.00 & 64.84 & 64.54 & 73.45 & 1.75 & 0.032 & 0.040 & 0.498 \\
\hline $\mathrm{OM}$ & 79.86 & 79.65 & 78.31 & 83.32 & 0.88 & 0.173 & 0.538 & 0.140 \\
\hline Crude fat & 44.61 & 48.44 & 53.96 & 56.88 & 1.34 & 0.136 & $<0.001$ & 0.831 \\
\hline \multicolumn{9}{|l|}{ d 185} \\
\hline DM & 77.12 & 72.61 & 79.24 & 71.82 & 1.67 & 0.103 & 0.843 & 0.666 \\
\hline $\mathrm{CP}$ & 72.46 & 72.45 & 75.08 & 73.35 & 0.67 & 0.550 & 0.240 & 0.550 \\
\hline $\mathrm{OM}$ & 82.93 & 81.67 & 82.14 & 80.54 & 0.51 & 0.198 & 0.372 & 0.867 \\
\hline Crude fat & 50.52 & 48.48 & 57.72 & 56.74 & 1.34 & 0.320 & $<0.001$ & 0.720 \\
\hline
\end{tabular}

$D M$ dry matter, $C P$ crude protein, $O M$ organic matter

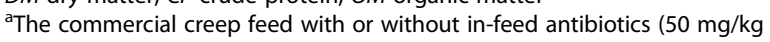
olaquindox, $50 \mathrm{mg} / \mathrm{kg}$ oxytetracycline calcium, and $50 \mathrm{mg} / \mathrm{kg}$ kitasamycin) was fed to pig from $\mathrm{d} 7$ to $\mathrm{d} 42$. Thereafter, the Con and Ant group were further randomly assigned to provide a normal $(20 \%, 18 \%, 14 \%$ CP from d 42 to $d 77$, d 77 to d 120 , d 120 to d 185 , respectively) or low CP diet (16\%, 14\%, $10 \%$ CP from $\mathrm{d} 42$ to $\mathrm{d} 77, \mathrm{~d} 77$ to $\mathrm{d} 120, \mathrm{~d} 120$ to $\mathrm{d} 185$, respectively), respectively. ${ }^{2}$ The $P$ values indicate main effects for antibiotic (Ant), protein level (CP) and their interaction (Ant $x \mathrm{CP})$, respectively

\section{Serum biochemical measurements}

To dissect whether EAI and dietary CP level affected the host metabolism, basic serum biochemistry was analyzed. On d 77, albumin, glucose, and urea concentrations in the serum revealed interactions $(P<0.05)$ between EAI and dietary $\mathrm{CP}$ treatments (Table 5). The EAI increased albumin and glucose concentrations in the low-CP diet, but increased urea concentration in the normal-CP diet. Meanwhile, EAI increased $(P<0.05)$ triglyceride concentration irrespective of dietary $\mathrm{CP}$, and tended to increase concentration of total protein $(P=0.08)$. The low-CP diet reduced $(P<0.05)$ concentrations of total protein and LDLC irrespective of EAI. On d 185, EAI also interacted with dietary $\mathrm{CP}$ on the concentrations of globulin and glucose in the serum $(P<0.05)$. The EAI decreased glucose concentration in normal-CP diet, but increased globulin concentration. Furthermore, low-CP diet reduced $(P<0.01)$ concentrations of urea, triglyceride, and HDLC irrespective of EAI. In general, these results indicated that EAI had short-term effects on serum parameters, and these effects may be influenced by dietary $\mathrm{CP}$ levels.

Table 5 Effects of early antibiotic intervention on serum biochemical indexes of pigs with different CP level diets ${ }^{1}$

\begin{tabular}{|c|c|c|c|c|c|c|c|c|}
\hline \multirow[t]{2}{*}{ Item } & \multicolumn{2}{|l|}{ Low-CP } & \multicolumn{2}{|c|}{ Normal-CP } & \multirow[t]{2}{*}{ SEM } & \multicolumn{3}{|l|}{$P$-value ${ }^{2}$} \\
\hline & Con & Ant & Con & Ant & & Ant & $\mathrm{CP}$ & Ant $\times C P$ \\
\hline \multicolumn{9}{|l|}{ d 77} \\
\hline Total protein, g/L & 62.00 & 66.21 & 63.61 & 70.79 & 1.67 & 0.082 & 0.031 & 0.643 \\
\hline Albumin, g/L & $17.73^{b}$ & $23.20^{\mathrm{a}}$ & $18.04^{b}$ & $19.45^{b}$ & 0.66 & $<0.001$ & 0.122 & 0.049 \\
\hline Globulin, g/L & 44.27 & 43.01 & 45.57 & 51.34 & 1.73 & 0.553 & 0.178 & 0.342 \\
\hline Glucose, mmol/L & $4.39^{c}$ & $5.58^{\mathrm{a}}$ & $5.44^{\mathrm{ab}}$ & $5.26^{\mathrm{b}}$ & 0.14 & 0.004 & 0.189 & 0.002 \\
\hline Urea, mmol/L & $2.12^{\mathrm{b}}$ & $2.16^{\mathrm{b}}$ & $2.46^{\mathrm{b}}$ & $3.26^{\mathrm{a}}$ & 0.12 & 0.003 & $<0.001$ & 0.003 \\
\hline Cholesterol, mmol/L & 1.87 & 1.89 & 1.97 & 2.09 & 0.05 & 0.890 & 0.223 & 0.080 \\
\hline Triglyceride, $\mathrm{mmol} / \mathrm{L}$ & 0.45 & 0.60 & 0.63 & 0.75 & 0.03 & 0.039 & 0.145 & 0.323 \\
\hline $\mathrm{HDLC}, \mathrm{mmol} / \mathrm{L}$ & 0.77 & 0.81 & 0.84 & 0.88 & 0.02 & 0.132 & 0.651 & 0.241 \\
\hline $\mathrm{LDLC}, \mathrm{mmol} / \mathrm{L}$ & 1.03 & 0.99 & 1.04 & 1.14 & 0.04 & 0.430 & 0.045 & 0.603 \\
\hline \multicolumn{9}{|l|}{ d 185} \\
\hline Total protein, g/L & 66.62 & 65.14 & 65.26 & 69.34 & 1.45 & 0.378 & 0.342 & 0.072 \\
\hline Albumin, g/L & 31.60 & 32.64 & 33.48 & 31.78 & 0.73 & 0.664 & 0.489 & 0.081 \\
\hline Globulin, g/L & $35.02^{\mathrm{ab}}$ & $32.50^{b}$ & $31.78^{b}$ & $37.56^{\mathrm{a}}$ & 1.56 & 0.313 & 0.567 & 0.022 \\
\hline Glucose, $\mathrm{mmol} / \mathrm{L}$ & $4.54^{b}$ & $4.88^{b}$ & $5.54^{\mathrm{a}}$ & $4.78^{b}$ & 0.12 & 0.245 & 0.021 & 0.011 \\
\hline Urea, mmol/L & 4.38 & 4.12 & 5.02 & 6.04 & 0.26 & 0.352 & 0.004 & 0.134 \\
\hline Cholesterol, mmol/L & 2.10 & 1.97 & 2.15 & 2.20 & 0.07 & 0.793 & 0.322 & 0.542 \\
\hline Triglyceride, mmol/L & 0.46 & 0.45 & 0.61 & 0.57 & 0.03 & 0.684 & 0.020 & 0.743 \\
\hline $\mathrm{HDLC}, \mathrm{mmol} / \mathrm{L}$ & 0.85 & 0.77 & 0.91 & 0.95 & 0.02 & 0.593 & 0.011 & 0.151 \\
\hline LDLC, mmol/L & 0.99 & 0.99 & 1.01 & 0.91 & 0.04 & 0.572 & 0.712 & 0.574 \\
\hline
\end{tabular}

$H D L C$, high density lipoprotein-cholesterol, $L D L C$, low density lipoprotein-cholesterol

${ }^{a-c}$ Means in the same row with different superscripts differ $(P<0.05)$

${ }^{1} T$ The commercial creep feed with or without in-feed antibiotics $(50 \mathrm{mg} / \mathrm{kg}$ olaquindox, $50 \mathrm{mg} / \mathrm{kg}$ oxytetracycline calcium, and $50 \mathrm{mg} / \mathrm{kg}$ kitasamycin) was fed to pig from $d 7$ to $d 42$. Thereafter, the Con and Ant group were further randomly assigned to provide a normal $(20 \%, 18 \%, 14 \% \mathrm{CP}$ from $\mathrm{d} 42$ to $d 77$, $d 77$ to $d$ $120, \mathrm{~d} 120$ to $\mathrm{d} 185$, respectively) or low CP diet $\left(16 \%, 14 \%, 10 \% \mathrm{CP}\right.$ from d 42 to $\mathrm{d} 77, \mathrm{~d} 77$ to $\mathrm{d} 120, \mathrm{~d} 120$ to $\mathrm{d} 185$, respectively), respectively. ${ }^{2}$ The $P$ values indicate main effects for antibiotic (Ant), protein level (CP) and their interaction (Ant $x$ CP), respectively 
Fecal bacterial populations

In order to evaluate the effect of EAI on the quantitative change of bacterial community in the feces, real-time PCR was performed on some major bacterial groups. As shown in Additional file 1: Figure S1, dietary treatments had no effects on fecal major bacterial population on $\mathrm{d}$ 77 and d 185, such as total bacteria, Firmicutes, Bacteroidetes, Clostridium cluster IV, and Clostridium cluster XIVa. However, on d 77 (Fig. 1a), EAI significantly decreased $(P<0.05)$ the counts of E. coli, and tended to reduce the counts of Lactobacillus $(P=0.09)$. Meanwhile, the low-CP diet also reduced the count of $E$. coli $(P<0.05)$. On $\mathrm{d} 185$ (Fig. 1b), pigs with low-CP diet tended to record a lower count of Lactobacillus $(P=0.09)$. Overall, these results suggest that the effect of EAI and dietary CP levels on bacterial groups in the fecal samples was limited except for $E$. coli.

\section{Fermentation metabolites in fecal contents}

To understand whether EAI affect fecal fermentation profiles with different $\mathrm{CP}$ diets, fermentation metabolites were determined. For SCFA (Fig. 1), EAI and low-CP diet did not affect fecal total SCFA, acetate, butyrate, isobutyrate, valerate, and isovalerate concentrations on $\mathrm{d} 77$ (Fig. 1a), but the low-CP diet tended to reduce $(P=0.088)$ propionate concentration. On $\mathrm{d} 185$ (Fig. 1b), EAI did not change the SCFA concentrations among groups in the present study. However, the low-CP diet decreased $(P<0.05)$ total SCFA, acetate, propionate, isobutyrate, and isovalerate concentrations.

Ammonia was produced through amino acids deamination by bacteria. On d 77, EAI did not affect the concentration of ammonia (data not shown). The low$\mathrm{CP}$ diet significantly decreased $(P<0.05)$ ammonia concentration in feces. On d 185, dietary treatment did not affect ammonia concentration.

Amines are formed from the decarboxylation of proteins, amino acids, and other nitrogenous compounds in the GIT. As shown in Fig. 2, cadaverine and putrescine are the main amines. On d 77 (Fig. 2a), EAI significantly decreased $(P<0.05)$ the concentration of total amines, cadaverine, and increased $(P<0.05)$ the concentration of tryptamine. The low-CP diet significantly decreased $(P<0.05)$ cadaverine, tyramine, methylamine, and tryptamine concentrations. However, the concentrations of putrescine, spermidine, and spermine were not affected by dietary treatment. On d 185 (Fig. 2b), there

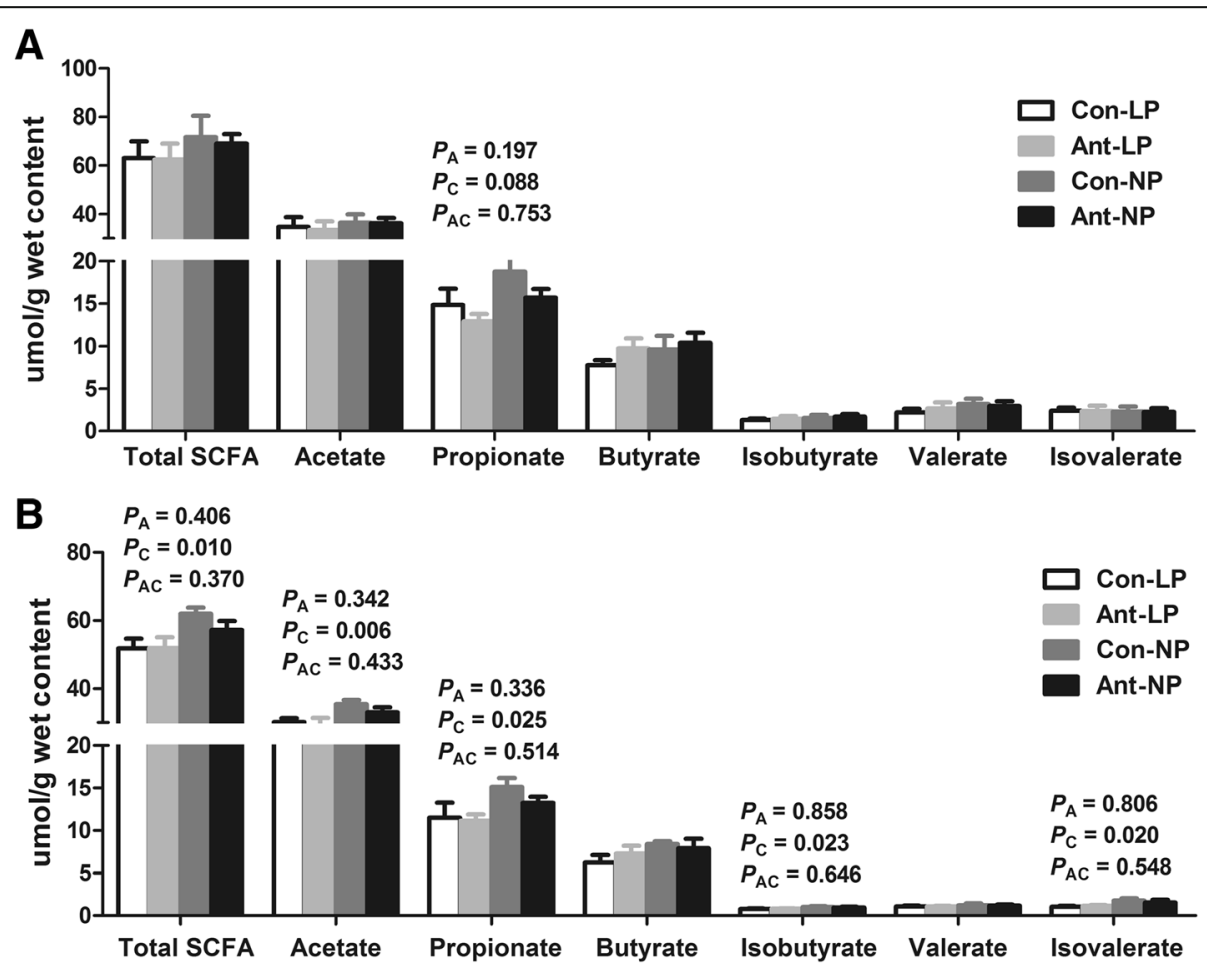

Fig. 1 Effects of EAl on SCFAs concentrations in the feces of pigs with different CP levels diets. (Con-LP, $\square$ Ant-LP, $\square$; Con-NP, $\square$; Ant-NP, $\square$ ) a On d 77. b On d 185. EAl: early antibiotic intervention. Total SCFA, total short-chain fatty acid. The commercial creep feed with or without in-feed antibiotics (50 mg/kg olaquindox, $50 \mathrm{mg} / \mathrm{kg}$ oxytetracycline calcium, and $50 \mathrm{mg} / \mathrm{kg}$ kitasamycin) was fed to pig from d 7 to $\mathrm{d} 42$. Thereafter, the control and antibiotic group were further randomly assigned to provide a normal (20\%, 18\%, 14\% CP from d 42 to $d 77, d 77$ to d 120, d 120 to d 185, respectively) or low CP $\operatorname{diet}(16 \%, 14 \%, 10 \%$ CP from d 42 to $d 77, d 77$ to $d 120, d 120$ to $d 185$, respectively), respectively. The $P$ values indicate main effects for antibiotic (A), protein level $(C)$ and their interaction $(A C)$, respectively 


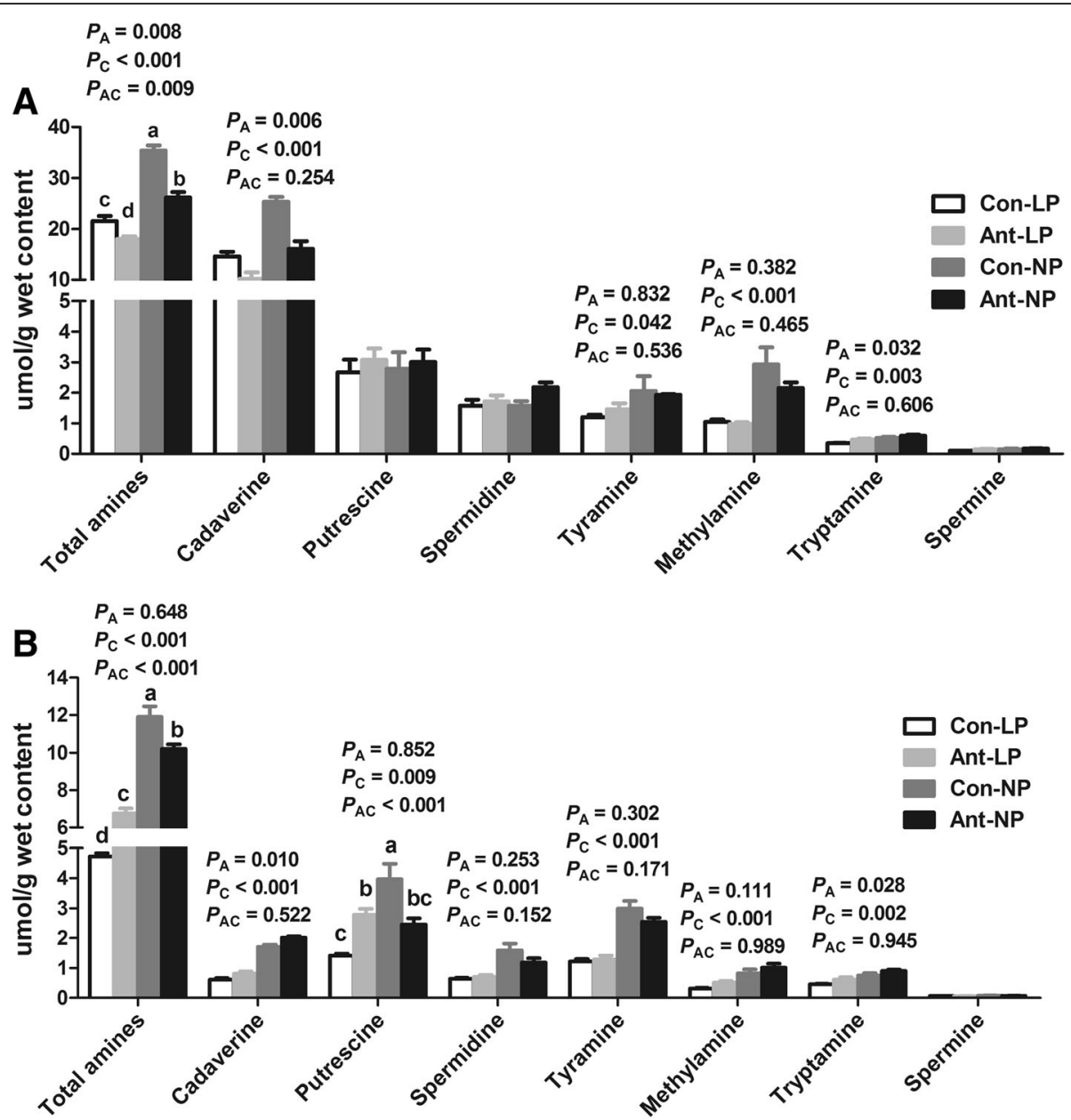

Fig. 2 Effects of EAl on amines concentrations in the feces of pigs with different CP levels diets. (Con-LP, $\square$; Ant-LP, $\square$; Con-NP, $\square$; Ant-NP, a On d 77. b On d 185. EAl: early antibiotic intervention. The commercial creep feed with or without in-feed antibiotics (50 mg/kg olaquindox, $50 \mathrm{mg} / \mathrm{kg}$ oxytetracycline calcium, and $50 \mathrm{mg} / \mathrm{kg}$ kitasamycin) was fed to pig from d 7 to $\mathrm{d} 42$. Thereafter, the control and antibiotic group were further randomly assigned to provide a normal (20\%, 18\%, 14\% CP from d 42 to $\mathrm{d} 77, \mathrm{~d} 77$ to d 120, d 120 to d 185, respectively) or low CP diet (16, $14,10 \%$ CP from d 42 to $d 77, d 77$ to $d 120$, d 120 to $d 185$, respectively), respectively. The $P$ values indicate main effects for antibiotic (A), protein level (C) and their interaction (AC), respectively

was an interaction $(P<0.001)$ between EAI and dietary CP level for putrescine. The EAI reduced $(P<0.05)$ concentrations of putrescine in normal-CP diet, but increased its concentration of $(P<0.05)$ in low-CP diet. Additionally, EAI increased $(P<0.05)$ the concentrations of tryptamine and cadaverine. The low-CP diet decreased $(P<0.01)$ the concentrations of total amines, methylamine, tryptamine, putrescine, cadaverine, tyramine, and spermidine.

Phenolic and indolic compounds originate from the intestinal degradation of aromatic amino acids. As shown in Fig. 3, there was an interaction $(P<0.05)$ between EAI and dietary CP level for skatole concentration on d 77 (Fig. 3a). The EAI significantly increased $(P<0.05)$ concentration of skatole in low-CP diets, but not in normal-CP diet. Furthermore, pigs with low-CP diet reduced the concentrations of $p$-cresol and indole
$(P<0.05)$. There was no dietary treatment effect on phenol concentration. On d 185 (Fig. 3b), the EAI did not affect the concentrations of phenol, $p$-cresol, and skatole, but tended to reduce $(P=0.08)$ indole concentration. The low-CP diet decreased $(P<0.05)$ the concentration of phenol and skatole but increased $(P<0.05)$ concentration of $p$-cresol. Collectively, these results indicated that EAI had a great impact on metabolites of protein fermentation in feces, but had little effect on carbohydrate fermentation. The low-CP diets reduced the protein fermentation products in feces on both $\mathrm{d} 77$ and $\mathrm{d} 185$.

\section{Discussion}

By employing a whole growth stage continuous feeding strategy, the current experiment enabled to evaluate the short- (77 d) and long-term (185 d) effect of EAI (from $\mathrm{d} 7$ to $\mathrm{d} 42$ ) on pig blood parameters, apparent nutrient 

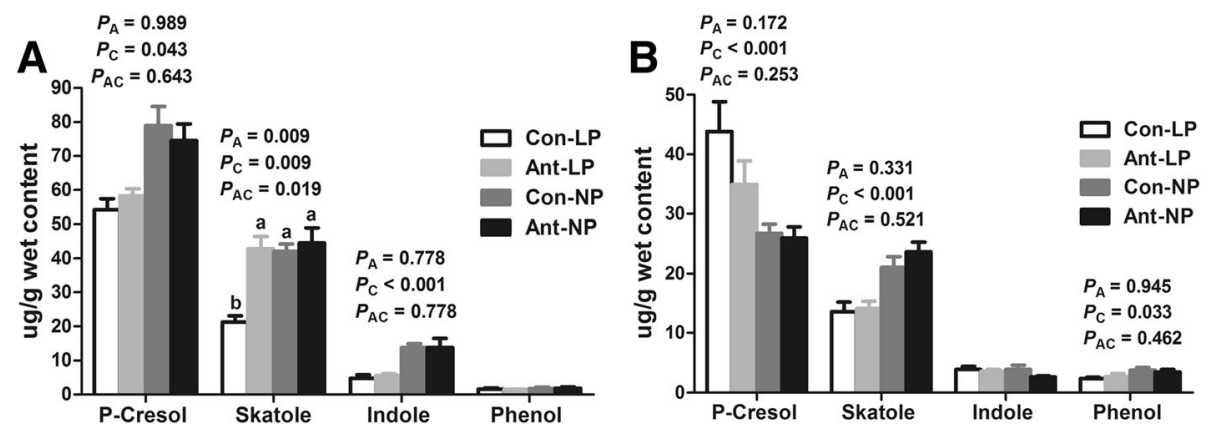

Fig. 3 Effects of EAl on phenolic and indole compounds concentrations in the feces of pigs with different CP levels diets. (Con-LP, $\square$ Ant-LP, ; Con-NP, _ Ant-NP, a a On d 77. b On d 185. EAl: early antibiotic intervention. The commercial creep feed with or without in-feed antibiotics (50 mg/kg olaquindox, $50 \mathrm{mg} / \mathrm{kg}$ oxytetracycline calcium, and $50 \mathrm{mg} / \mathrm{kg}$ kitasamycin) was fed to pig from d 7 to $\mathrm{d} 42$. Thereafter, the control and antibiotic group were further randomly assigned to provide a normal $(20 \%, 18 \%, 14 \%$ CP from d 42 to $d 77, d 77$ to $\mathrm{d} 120, \mathrm{~d} 120$ to $\mathrm{d} 185$, respectively) or low CP diet $(16,14,10 \%$ CP from d 42 to $\mathrm{d} 77, \mathrm{~d} 77$ to $\mathrm{d} 120, \mathrm{~d} 120$ to d 185, respectively), respectively. The $P$ values indicate main effects for antibiotic (A), protein level (C) and their interaction (AC), respectively

digestibility, microbial metabolism, and bacterial counts in feces with different dietary CP level. Our results suggested that the EAI had short-term effects on blood parameters and microbial fermentation products in pigs, and that these effects were influenced by dietary CP levels.

In the intestine, there are differences in microbiome between gut segments and between fecal samples and intestinal samples. Along the hindgut fermentation in the pig (from cecum to distal colon), proportionally carbohydrate fermentation decreases while proteolytic fermentation increases. However, fecal samples are easy to access and easy for practice, and also can partly, though not exactly, reflect the general microbial metabolism in the gut. Thus, fecal samples are commonly used in many researches for host metabolism in humans and animals. In the present study, we intended to reflect the general gut metabolism through fecal samples analysis and the results showed that an alteration in microbial fermentation profiles of amino acid by dietary treatment, indicating that EAI and CP level affected the gut microbial composition and function. This approach by using fecal analysis can provide a feasible way to study the effects of EAI and CP on fermentation profiles of microbial amino acid metabolism.

\section{Effects of early antibiotic intervention on growth} performance and blood parameters with different protein levels after antibiotic withdrawal

At present, information on the effects of EAI on subsequent growth performance under different dietary $\mathrm{CP}$ levels is limited. Skinner et al. [25] reported that the use of antibiotics (therapeutic dose usage) in the nursery diets with normal-CP level appeared to reduce subsequent ADG of the pigs as compared to non-treated controls. In the present study, the antibiotics at low dosage did not have effect on subsequent ADG with normal-CP diet, though increased the subsequent ADG under low$\mathrm{CP}$ diet. Thus, the antibiotic effect on subsequent growth performance may vary depending on the antibiotic dosage and the diet CP level.

The level of serum parameters of animals reflects the body metabolic status according to their internal and external environments [26]. EAI exerted an effect on body metabolism on $\mathrm{d} 77$, such as a significant increase of the concentrations of albumin and glucose, especially in low-CP diets, but not in normal-CP diets. A previous study also indicated that pigs received therapeutic amoxicillin exposure at birth through postnatal d 14 increased glucose concentration at postnatal d 49 [8]. Additionally, we found that the antibiotics effect on serum biochemistry was diminished on d 185. Thus, antibiotic intervention showed short-term effect on body metabolism, but had no long-term effect.

\section{Effects of early antibiotic intervention on fermentation profiles of microbial amino acid metabolism with different protein levels after antibiotic withdrawal}

Antibiotics are usually considered the most cost-effective way to reduce pathogenic bacteria [1]. Based on the microbiota analyses, we found that EAI had limited effect on the bacterial composition, only decreased the numbers of $E$. coli counts in the fecal samples irrespective of dietary CP levels on $\mathrm{d} 77$, which suggested that EAI had limited long-term impact on fecal microbiota. Janczyk et al. [27] observed that piglets treated with amoxicillin $(15 \mathrm{mg} / \mathrm{kg}$ body weight) by intramuscular administration at $\mathrm{d} 1$ showed a decreased microbial diversity in colon on $\mathrm{d} 39$. Collectively, these findings suggest that EAI less affected bacterial communities in feces.

EAI also affected profiles of biogenic amimes in the pig feces. The significant decrease of cadaverine and total amines concentrations suggested a decreased amino acid 
decarboxylation after EAI treatment. High concentration of cadaverine can exert detrimental effects on the host, such as inducing DNA damage and oxidative stress [28]. Thus, the decrease of cadaverine and total amines concentration by EAI may exert a beneficial influence on the host. Coincidently, among the bacteria examined in the present study, E. coli species are a major proteinfermenting group [29]. Our previous study indicated that the cadaverine concentration was positively correlated with the abundance of $E$. coli [12]. Therefore, the decrease of cadaverine concentration by EAI may be due to the decrease in protein-fermenting bacteria counts $(E$. coli) and the subsequent reduction of the catabolism of precursor amino acid (lysine). EAI increased putrescine concentration in low-CP diet but decreased it in normal-CP diet. This results indicates that the effect of EAI on subsequent concentrations of amines may vary with CP level. Furthermore, we found that cadaverine concentration varied between d 77 and d 185. Cadaverine is derived from decarboxylation of lysine [30]. In the current study, the $\mathrm{CP}$ level and lysine concentration in the diet was much higher on $\mathrm{d} 77$ than $185 \mathrm{~d}$, which may lead to the variation in cadaverine concentration across ages.

On the other hand, EAI also changed aromatic amino acid metabolism by the microbes in the GIT. Tryptophan, one of the aromatic amino acid, can be decarboxylated into tryptamine by GIT microbes [30, 31]. In the present study, EAI increased tryptamine concentration in the feces irrespective dietary CP levels on d 77 and d 185, suggesting that EAI had a continuous effect on aromatic amino acid metabolism. Tryptamine can stimulate the secretion of serotonin by enterochromaffin cells, and then regulate intestinal motility [32].Thus, an increase of tryptamine may affect the function of intestine. Additionally, EAI also increased skatole concentration on d 77, especially in lowCP diets. Skatole is produced from tryptophan catabolism by GIT bacteria [30]. The increase of skatole concentration indicates that EAI also affected tryptophan catabolism in the gut. Collectively, combined with serum parameters and microbial fermentation profiles, the effects of EAI persisted to short-term after withdrawal, but weakened at finishing period of the pigs.

\section{Low-CP diets affected host metabolism and fermentation profiles of microbial amino acid metabolism}

In our study, low-CP dietary treatment affected the urea metabolism as reflected by the decreased urea concentration in serum both on $\mathrm{d} 77$ and d 185, which has also been found in other reports $[33,34]$. Urea is the main nitrogenous end product of amino acids catabolism in pigs. A decrease in serum urea level is indicative of a more efficient use of dietary nitrogen [35]. Thus, our study may indicate that low-CP diet affected nitrogen metabolism in pigs.
Corresponding to the decrease in urea concentration in serum, low-CP diet markedly affected the microbial metabolism of amino acids in the intestine, as shown by the decrease in concentration of most amines, suggesting decreased microbial decarboxylation. Furthermore, low-CP diet decreased some phenolic and indole compounds concentrations. Indole and skatole are products of tryptophan metabolism originating from dietary and endogenous protein [31]. Although the concentration of tryptophan in the normal-CP diet is equal to that of the low-CP diet in the current study, crystalline amino acid is quickly absorbed before reaching the hindgut, and then reduced the availability of substrates for microbial fermentation in the hindgut. Overall, these findings suggest that low-CP diets significantly reduced the microbial fermentation of protein or amino acids and the concentration of potentially harmful metabolites derived from microbial metabolism of feed-derived amino acids. Thus, the dietary nitrogen was used more efficiently with low level of potentially harmful metabolites in pigs fed low-CP amino acids-supplemented diets.

Low-CP diets altered the markers of microbial carbohydrate metabolism on $\mathrm{d} 185$, such as decreased the concentrations of acetate, propionate, isobutyrate, isovalerate, and total SCFA, consistent with Le et al. [36], who observed that reducing dietary CP level from $15 \%$ to $12 \%$ led to a decrease in total SCFA, acetate, and propionate concentrations for finishing pigs. The concentration of SCFA produced mainly depends on the amount and composition of substrate and the type of microbes present in the GIT [37]. Thus, in the present study, a decrease of SCFAs may be related with the altered metabolism activity of gut microbiota after low-CP diet.

\section{Conclusions}

In conclusion, combined with the changes in blood metabolites, digestibility, and microbial metabolite, our results showed that EAI (from d 7 to d 42) showed short-term effects on pigs, especially on the body and microbial metabolism. The effects of EAI varied between CP levels, which was characterized by the significant alteration of glucose and putrescine concentration. The low-CP diet significantly decreased the amino acids fermentation products in feces.

\section{Additional file}

Additional file 1: Table S1. Ingredients and chemical composition of creep feed diets. Figure S1. Effects of early antibiotic intervention on bacterial abundance in the feces of pigs with different $C P$ levels diets. (Con-LP, White; Ant-LP, Light gray; Con-NP, Dark gray; Ant-NP, Black ). A: On d 77. B: On d 185. The commercial creep feed with or without in-feed antibiotics (50 mg/kg olaquindox, $50 \mathrm{mg} / \mathrm{kg}$ oxytetracycline calcium, and $50 \mathrm{mg} / \mathrm{kg}$ kitasamycin) was fed to pig from d 7 to $\mathrm{d} 42$. Thereafter, the control and antibiotic group were further randomly assigned to provide a 
normal $(20 \%, 18 \%, 14 \%$ CP from d 42 to $d 77, d 77$ to $d 120, d 120$ to $d 185$ respectively) or low CP diet $(16 \%, 14 \%, 10 \%$ CP from $d 42$ to $d 77, d 77$ to $d$ 120 , d 120 to $d 185$, respectively), respectively. The $P$ values indicate main effects for antibiotic (A), protein level (C) and their interaction (AC), respectively. (DOC $576 \mathrm{~kb})$

\section{Abbreviations}

ADFI: average daily feed intake; ADG: average daily gain; AIA: acid-insoluble ash; BCFA: branched-chain fatty acid; BW: body weight; CP: crude protein DW: dry matter; EAl: early antibiotic intervention; G:F: the ratio of gain to feed; GIT: gastrointestinal bacteria; HDLC: high density lipoprotein cholesterol; LDLC: Iow density lipoprotein cholesterol; OM: organic matter; SCFA: short chain fatty acid

\section{Acknowledgements}

The authors sincerely thanks to Professor Sung Woo Kim of North Carolina State University for his critical discussion and reading during manuscript preparation.

\section{Funding}

This work was supported by National Key Basic Research Program of China (2013CB127300) and Natural Science Foundation of China (31430082). The funders had no role in the design of the study, collection, analysis, and interpretation of data and in writing of the manuscript.

\section{Availability of data and materials}

The datasets supporting the conclusions of this article are included within the article

\section{Authors' contributions}

The author' contributions are as follows: WYZ and YS were in charge of the whole trial; MY and WYZ wrote the manuscript; CLM and YXY for animal feeding and care; KFY, MY and CJZ assisted with sampling and laboratory analyses. All authors read and approved the final manuscript.

\section{Ethics approval}

The experimental proposals and procedures for the care and treatment of the pigs were approved by the Animal Care and Use Committee of Nanjing Agricultural University, in accordance with the Regulations for the Administration of Affairs Concerning Experimental Animals.

\section{Consent for publication}

Not applicable.

\section{Competing interests}

The authors declare that they have no competing interests.

Received: 20 December 2016 Accepted: 20 June 2017

Published online: 01 August 2017

\section{References}

1. Cromwell GL. Why and how antibiotics are used in swine production. Anim Biotechnol. 2002;13:7-27

2. Puiman P, Stoll B, Mølbak L, de Bruijn A, Schierbeek H, Boye M, et al. Modulation of the gut microbiota with antibiotic treatment suppresses whole body urea production in neonatal pigs. Am J Physiol-Gastr L. 2013;304:300-10.

3. Yoon JH, Ingale SL, Kim JS, Kim KH, Lohakare J, Park YK, et al. Effects of dietary supplementation with antimicrobial peptide-P5 on growth performance, apparent total tract digestibility, faecal and intestinal microflora and intestinal morphology of weanling pigs. J Sci Food Agr. 2013;93:587-92.

4. Rettedal E, Vilain S, Lindblom S, Lehnert K, Scofield C, George S, et al. Alteration of the ileal microbiota of weanling piglets by the growth-promoting antibiotic chlortetracycline. Appl Environ Microb. 2009;75:5489-95.

5. Looft T, Johnson TA, Allen HK, Bayles DO, Alt DP, Stedtfeld RD, et al. In-feed antibiotic effects on the swine intestinal microbiome. P Natl Acad Sci USA 2012:109:1691-6.

6. Dierick N, Vervaeke I, Decuypere J, Henderickx H. Influence of the gut flora and of some growth-promoting feed additives on nitrogen metabolism in pigs. I. Studies in vitro. Livest Prod Sci. 1986;14:161-76.
7. Bhandari S, Xu B, Nyachoti C, Giesting D, Krause D. Evaluation of alternatives to antibiotics using an K88 model of piglet diarrhea: effects on gut microbial ecology. J Anim Sci. 2008;86:836-47.

8. Li J, Yang K, Ju T, Ho T, McKay CA, Gao Y, et al. Early life antibiotic exposure affects pancreatic islet development and metabolic regulation. Sci Rep. 2017:7:41778.

9. Schokker D, Zhang J, Vastenhouw SA, Heilig HG, Smidt H, Rebel JM, et al. Long-lasting effects of early-life antibiotic treatment and routine animal handling on gut microbiota composition and immune system in pigs. PLoS One. 2015;10:e0116523.

10. Cho I, Yamanishi S, Cox L, Methé BA, Zavadil J, Li K, et al. Antibiotics in early life alter the murine colonic microbiome and adiposity. Nature. 2012:488:621-6.

11. Cox LM, Yamanishi S, Sohn J, Alekseyenko AV, Leung JM, Cho I, et al. Altering the intestinal microbiota during a critical developmental window has lasting metabolic consequences. Cell. 2014;158:705-21.

12. Mu CL, Yang YX, Luo Z, Guan LL, Zhu WY. The colonic microbiome and epithelial transcriptome are altered in rats fed a high-protein diet compared with a normal-protein diet. J Nutr. 2016;146:474-83.

13. Luo Z, Li C, Cheng Y, Hang S, Zhu W. Effects of low dietary protein on the metabolites and microbial communities in the caecal digesta of piglets. Arch Anim Nutr. 2015;69:212-26.

14. Zhang CJ, Yu M, Yang YX, Mu CL, Su Y, Zhu WY. Effect of early antibiotic administration on cecal bacterial communities and their metabolic profiles in pigs fed diets with different protein levels. Anaerobe. 2016:42:188-96

15. Mu CL, Yang YX, Yu KF, Yu M, Zhang CJ, Su Y, et al. Alteration of metabolomic markers of amino-acid metabolism in piglets with in-feed antibiotics. Amino Acids. 2017;49(4):771-81.

16. NRC. Nutrient requirements of swine. 11th ed. Washington, DC: Natl Acad Press; 2012

17. AOAC. Official methods of analysis. 18th ed. Association of Official Analytical Chemists: Gaithersburg, MD; 2007.

18. ISO. Animal feeding stuffs-determination of ash insoluble in hydrochloric acid (ISO 5985). Geneva, Switzerland: International Organization for Standardization; 2003.

19. McCarthy J, Aherne F, Okai D. Use of $\mathrm{HCl}$ insoluble ash as an index material for determining apparent digestibility with pigs. Can J Anim Sci. 1974:54:107-9.

20. Zoetendal EG, Akkermans ADL, Vos WMD. Temperature gradient gel electrophoresis analysis of 165 rRNA from human fecal samples reveals stable and host-specific communities of active bacteria. Appl Environ Microb. 1998;64:3854-9.

21. Wang X, Mao S, Liu J, Zhang L, Cheng Y, Jin W, et al. Effect of gynosaponins on methane production and microbe numbers in a fungus-methanogen co-culture. J Anim Feed Sci. 2011:20:272-84.

22. Yang $Y X, M u C L$, Zhang JF, Zhu WY. Determination of biogenic amines in Digesta by high performance liquid chromatography with Precolumn Dansylation. Anal Lett. 2014;47:1290-8.

23. Chaney AL, Marbach EP. Modified reagents for determination of urea and ammonia. Clin Chem. 1962:8:130-2.

24. Jensen MT, Cox RP, Jensen BB. 3-Methylindole (skatole) and indole production by mixed populations of pig fecal bacteria. Appl Environ Microbiol. 1995:61:3180-4.

25. Skinner L, Levesque C, Wey D, Rudar M, Zhu J, Hooda S, et al. Impact of nursery feeding program on subsequent growth performance, carcass quality, meat quality, and physical and chemical body composition of growing-finishing pigs. J Anim Sci. 2014;92:1044-54.

26. Nicholson JK, Holmes E, Kinross JM, Darzi AW, Takats Z, Lindon JC. Metabolic phenotyping in clinical and surgical environments. Nature. 2012:491:384-92.

27. Janczyk P, Pieper R, Souffrant WB, Bimczok D, Rothkötter H-J, Smidt H Parenteral long-acting amoxicillin reduces intestinal bacterial community diversity in piglets even 5 weeks after the administration. ISME J. 2007;1:180-3.

28. Holmes E, Li JV, Athanasiou T, Ashrafian H, Nicholson JK. Understanding the role of gut microbiome-host metabolic signal disruption in health and disease. Trends Microbiol. 2011;19:349-59.

29. Rist VT, Weiss E, Sauer N, Mosenthin R, Eklund M. Effect of dietary protein supply originating from soybean meal or casein on the intestinal microbiota of piglets. Anaerobe. 2014:25:72-9.

30. Davila A-M, Blachier F, Gotteland M, Andriamihaja M, Benetti P-H, Sanz Y, et al. Intestinal luminal nitrogen metabolism: role of the gut microbiota and consequences for the host. Pharmacol Res. 2013;68:95-107. 
31. Rist V, Weiss E, Eklund M, Mosenthin R. Impact of dietary protein on microbiota composition and activity in the gastrointestinal tract of piglets in relation to gut health: a review. Animal. 2013;7:1067-78.

32. Yano JM, Yu K, Donaldson GP, Shastri GG, Ann P, Ma L, et al. Indigenous bacteria from the gut microbiota regulate host serotonin biosynthesis. Cell. 2015;161:264-76.

33. Nyachoti C, Omogbenigun F, Rademacher M, Blank G. Performance responses and indicators of gastrointestinal health in early-weaned pigs fed low-protein amino acid-supplemented diets. J Anim Sci. 2006;84:125-34.

34. Yue L, Qiao S. Effects of low-protein diets supplemented with crystalline amino acids on performance and intestinal development in piglets over the first 2 weeks after weaning. Livest Sci. 2008;115:144-52.

35. Figueroa J, Lewis A, Miller PS, Fischer R, Gómez R, Diedrichsen R. Nitrogen metabolism and growth performance of gilts fed standard corn-soybean meal diets or low-crude protein, amino acid-supplemented diets. J Anim Sci. 2002;80:2911-9.

36. Le P, Aarnink A, Jongbloed A. Odour and ammonia emission from pig manure as affected by dietary crude protein level. Livest Sci. 2009;121:267-74.

37. van Beers-Schreurs HM, Nabuurs MJ, Vellenga L, Kalsbeek-van der Valk HJ, Wensing T, Breukink HJ. Weaning and the weanling diet influence the villous height and crypt depth in the small intestine of pigs and alter the concentrations of short-chain fatty acids in the large intestine and blood. J Nutr. 1998;128:947-53.

38. Suzuki MT, Taylor LT, DeLong EF. Quantitative analysis of small-subunit rRNA genes in mixed microbial populations via 5'-nuclease assays. Appl Environ Microbiol. 2000:66:4605-14.

39. Guo X, Xia X, Tang R, Zhou J, Zhao H, Wang K. Development of a real-time PCR method for Firmicutes and Bacteroidetes in faeces and its application to quantify intestinal population of obese and lean pigs. Lett Appl Microbiol. 2008:47:367-73.

40. Matsuki T, Watanabe K, Fujimoto J, Takada T, Tanaka R. Use of $16 \mathrm{~S}$ rRNA genetargeted group-specific primers for real-time PCR analysis of predominant bacteria in human feces. Appl Environ Microbiol. 2004;70:7220-8.

41. Bartosch S, Fite A, Macfarlane GT, McMurdo ME. Characterization of bacterial communities in feces from healthy elderly volunteers and hospitalized elderly patients by using real-time PCR and effects of antibiotic treatment on the fecal microbiota. Appl Environ Microbiol. 2004:70:3575-81.

42. Huijsdens XW, Linskens RK, Mak M, Meuwissen SG, Vandenbroucke-Grauls CM, Savelkoul PH. Quantification of bacteria adherent to gastrointestinal mucosa by real-time PCR. J Clin Microbiol. 2002;40:4423-7.

43. Khafipour E, Li S, Plaizier JC, Krause DO. Rumen microbiome composition determined using two nutritional models of subacute ruminal acidosis. Appl Environ Microbiol. 2009;75:7115-24

\section{Submit your next manuscript to BioMed Central and we will help you at every step:}

- We accept pre-submission inquiries

- Our selector tool helps you to find the most relevant journal

- We provide round the clock customer support

- Convenient online submission

- Thorough peer review

- Inclusion in PubMed and all major indexing services

- Maximum visibility for your research

Submit your manuscript at www.biomedcentral.com/submit

) Biomed Central 